\title{
Semantic vs. Empirical Issues in the Bear Diversionary Baiting Controversy
}

\author{
Stephen F. Stringham ${ }^{1, *}$, Lynn L. Rogers ${ }^{2}$, Ann Bryant ${ }^{3}$ \\ ${ }^{1}$ Wild Watch, USA \\ ${ }^{2}$ Wildlife Research Institute, USA \\ ${ }^{3}$ BEAR League. USA
}

Copyright $(\subseteq 2017$ by authors, all rights reserved. Authors agree that this article remains permanently open access under the terms of the Creative Commons Attribution License 4.0 International License

\begin{abstract}
Conventional North American management of human-bear conflicts assumes that bears become more dangerous and destructive of human property if the bears have become food conditioned. Bears perceived as dangerous or destructive are usually killed. Conflict management to protect both people and bears focuses on minimizing bear access to anthropogenic foods. That can work where bears have access to sufficient wild foods. During famines of profitable wild foods, however, the key to minimizing conflicts can be providing food to bears so-called diversionary baiting. Wild food supply is only one of numerous factors determining why provisioning bears intensifies conflicts in some situations, but minimizes conflicts in other situations. Identifying and quantifying the role of each factor is best done through formation of a more comprehensive conceptual model, followed by hypothesis derivation and testing. Literature synthesis and paradigmatic reconceptualization have thus far been hampered by terminological ambiguity. To overcome this constraint, we propose systematically integrated definitions for key terms: (a) conflict zones and sites, conflict foods, provisioning, incursionary feeding, baiting for diversion and other purposes; (b) numerous sorts of food conditionning: respondant, instrumental, opportunistic, transient, compensatory, agonistically induced, preferential, locationspecific, person- specific, direct, indirect. (c) Food source descriptors: presence, abundance, density, accessibility, harvestability, availability, attractiveness, palatability, profitability, preference, reliability (predictability), and microhabitat suitability.
\end{abstract}

Keywords Black Bear, Brown Bear, Diversionary Baiting, Feeding, Food Conditioning, Grizzly Bear, Habituation, Ursus

\section{Introduction: Nature of the Controversy}

\subsection{Human-Bear Conflicts and Food Conditioning}

When a wild North American black bear (Ursus americanus) or brown/grizzly bear (U. arctos) injures a human or damages property (e.g., a home or vehicle), this is commonly attributed (a) to the bear not avoiding the person or property (i.e., to the bear being habituated), (b) to the bear being food conditioned and seeking anthropogenic food, and (c) to members of the public allowing bears access to such food. In many cases, agency managers and citizen stewards (e.g., the Bear League and Bear Smart organizations), have been able to substantially reduce conflicts by minimizing access, which in turn tends to minimize food conditioning and habituation [1-7]. Success has led to widespread belief that those tactics underlie any effective strategy to minimize conflicts. Where such a strategy fails, the blame is rarely placed on the strategy itself, but on alleged failure to fully implement its component tactics such that some food conditioned, habituated bears survive and still have access to anthropogenic foods. 


\subsection{Human-Bear Conflicts and Natural Food Scarcity}

Less attention has been paid to the underlying causes of attraction to anthropogenic foods - e.g., hunger for better nutrition than bears are obtaining from wild forage. Conventional wildlife management assumes that: (a) the bears which eat anthropogenic foods are either too lazy to forage for wild staples, or they simply prefer anthropogenic foods which are more palatable and/or nutritious than wild foods. In either event, the problem can allegedly be solved by forcing bears to subsist on wild forage - which they usually can, although sometimes at the expense of lower fitness. (b) However, in cases where wild foods don't suffice, perhaps because of famine - as in northeastern Minnesota during 1985 [8] and around Lake Tahoe on the California/Nevada border during the summer of 2007 [6,9], conventional wildlife management typically assumes that natural habitat carrying capacity has been exceeded - that it is too crowded with bears, so their density needs to be reduced through sport hunting. That assumption neglects cases where nutritional intake is not limited by the gross abundance of food (e.g., of salmon Oncorhynchus spp. or mast), but by how profitably it can be obtained and digested - as explained by optimal foraging theory [10] - which may be unrelated to bear population density. If bears can't survive on wild foods, then people making it harder for bears to obtain anthropogenic food increases famine's impacts on the bears. In our experience, it can also force bears to circumvent human precautions, which might increase the severity of their damage to houses and other property or heighten risk of human injury.

\subsection{Diversionary Baiting}

An alternate response to bear hunger is supplying wild bears with provisions at non-conflict sites. As conventional North American wildlife management lore would predict, some attempts at provisioning by the general public have actually exacerbated conflicts (Bryant unpubl. data). But done correctly according to protocols of diversionary baiting, provisioning has been successful in several experimental cases [6, 8-9, 11-17].

Cases have also been observed where conflict with black or brown bears was avoided or minimized although or because they regularly foraged on anthropogenic foods - e.g., (a) at several private homes in semi-rural areas of northeastern Minnesota and in a remote area of Alaska; (b) at garbage dumps in Minnesota, Michigan, northern New York, and Alaska; and (c) on salmon offal discarded by anglers on streams in Alaska. Although these highly food conditioned, habituated bears at dumps and salmon streams mingled with thousands of humans, few people have been harmed, and there has been little property damage. Granted, conflicts do sometimes occur at dumps [18] and salmon streams. But in the cases referenced above, success was at least as high as has been reported for conventional anti-conflict strategies. Even during lesser shortages of profitable wild foods, diversionary food sources at the homes of bear watchers can sometimes minimize even minor damage (e.g., to bird feeders) and visits by bears to homes where they are unwelcome. This has been demonstrated annually since 1961 at $12-17$ homes in one area of northeastern Minnesota $[8,19]$.

\subsection{Conflicts and Perceptions}

Conflict, like beauty, is partly in the eye of the beholder. The better that wildlife biologists and managers, as well as the general public, understand actual risks, and how risk level is affected by human actions and natural conditions, the less likely that the official and public views of bears will be distorted by seeing bears through either proverbial rose-colored glasses or blood-stained lenses.

\subsection{Denial and Biased Appraisal}

Claims that food conditioned, habituated bears are not necessarily troublesome or dangerous - but may instead be especially cooperative and safe under certain circumstances - have provoked disparagement by disciples of conventional strategies, even to the point of acrimonious statements in scientific venues and litigation in state courts. Likewise, in the uncommon event that someone has been injured by a bear that scavenges edible discards at a dump or salmon stream, critics have rushed to label these cases as proving that food conditioned bears are especially dangerous - rather than more reasonably and objectively assessing whether the rate of injury is higher than with bears that don't obtain anthropogenic food in such circumstances. Although respectful skepticism is heuristic, vitriolic skepticism isn't. 


\subsection{Objectivity and Resolving the Controversy}

Recognizing that food conditioning and habituation can intensify conflicts under some conditions, but alleviate conflicts under other conditions, requires a paradigm shift in thinking. It challenges researchers to (a) identify the additional variables which tip the outcome one way or the other, and to (b) integrate all of these factors into a more comprehensive conceptual model. For example, how is the outcome of bears obtaining anthropogenic food affected by how it is obtained, by the kinds of food obtained, or by the types of food conditioning and habituation? Then the model should be used to generate nuanced testable hypotheses. We also need common standards for judging the extent to which conflict has been intensified or alleviated by any given influence, and the cost-effectiveness of alternate management strategies.

\subsection{Semantics}

This is feasible only if one makes finer distinctions concerning key variables (e.g. types of food conditioning) than has been done conventionally. Also, each key term should be more precisely defined in a way which is not only less ambiguous, but systematically integrated with the other terms so that they form a unified mutually-consistent conceptual network. Otherwise, ambiguity can jeopardize the logic of discussions; and differences in semantics can be mistaken for differences in empirical observations, or vice versa. The terms and definitions proposed below were developed during the course of studying the behavior and ecology of bears that opportunistically foraged on handouts, baits, garbage or salmon offal in close proximity to humans. Our empirical findings, literature review, and conceptual model will be presented in a separate paper due to this journal's length constraints. These issues of food conditioning and habituation are not, of course, limited to bears [20]. Other large-bodied, relatively intelligent species that frequently conflict with humans include other carnivores (e.g., coyotes and wolves Canis latrans and C. lupus [21]), ungulates (e.g., Rocky mountain goats Oreamnos americanus [21], African elephants, Loxodonta africana [22, 23]) and primates (e.g., baboons Papio spp. [24]). Accordingly, the definitions given below are usually phrased generically in terms of "wildlife" or "wild animals."

\section{Terminology Related to Diversionary Baiting and Food Conditioning}

\subsection{Conflict Site:}

Any site where the presence of a wild animal is likely to conflict with a human.

- Within anthropogenic habitat: e.g., yards, homes, other buildings, or farms.

- Within wildland habitat: Sites with wild plants or animals whose value to humans is decreased by bears damaging them or eating them. Or sites where human use conflicts with bear use, or vice versa.

\subsection{Conflict Zone:}

A cluster of conflict sites, and the area encompassing them -- e.g., within a settlement, agricultural land, forest or river.

- Settlement: a campground, cluster of isolated buildings, town or city which might contain numerous sites with attractants (e.g., dumpsters and garbage cans).

- Agricultural land: e.g., garden, orchard, field, pasture, or fish hatchery.

- Forest: e.g., commercial conifers which are damaged by wildlife.

- River: e.g., where bears and anglers compete for migrating salmon (Oncorhynchus spp.).

\subsection{Conflict Food}

Any food whose harvest or consumption by wildlife, under given circumstances, tends to conflict with humans. Conflicts can arise due to either the kind of food, how it is obtained, or the location where it is obtained or eaten.

- Bears eating conifer cambium or berries is a conflict if this damages commercially valuable timber or interferes with berry harvest by people.

- Bears eating donuts is a conflict at bakeries, but not at hunter bait sites.

- Bears catching salmon doesn't conflict with bear viewers but it might conflict with anglers.

- Bears stealing harvested fish cooling in a stream near an angler. A bear intimidating an angler into surrendering salmon is a higher order conflict.

- The carcass of a deer being field-dressed by a hunter.

- The carcass of a deer hanging to age in a garage.

- Incursionary food. 


\subsection{Incursionary Food (IF) (one class of conflict food)}

Any food which promotes incursion into a conflict zone or site. Once an animal is eating one kind of $I F$, this might increase likelihood that the animal will also begin eating other foods common in that or other conflict zones.

\subsection{Feeding}

Government agencies and conservation groups, including the BEAR League and Bear Smart, have invested considerable resources teaching the public not to feed bears. Rather than seeming to contradict ourselves by now claiming that feeding is sometimes the right thing to do, both agency wildlife managers and public wildlife stewards might reserve the word "feeding" for providing nourishment to bears in ways that exacerbate conflicts. To avoid confusion, we preface it with the term "incursionary."

\subsection{Incursionary Feeding}

Providing food to a wild animal in a location or situation that is likely to increase conflicts between that animal and a human. Incursionary feeding need not be intentional (e.g., as when someone's garbage is not stored in a wildlife-proof container). In typical cases, conflicts arise because the food promotes incursion by the focal wildlife into a conflict zone, thereby increasing likelihoods that a focal animal will (a) damage property (e.g., buildings, vehicles, domestic animals, stored food, agricultural crops, etc.), (b) encounter someone who is uncomfortable being near the animal, or (c) rarely injure someone. In American states and Canadian provinces with a regulation against "feeding" bears, this corresponds to "incursionary" feeding, but not necessarily to "baiting" as defined herein. Even in some states where incursionary feeding is not specifically prohibited, it has been deemed a form of illegal harassment [25]. The same distinction can be made for other wildlife.

\subsection{Provisioning}

Purposefully providing a wild animal with food to benefit the animal or humans.

\subsection{Supplemental Provisioning}

Provisioning to improve an animal's nutritional status.

\subsection{Baiting}

Using an attractant (e.g., food) to lure an animal to or from a specific location. If the primary goal is luring an animal out of a conflict location/ situation, where the animal ends up might be of little concern. Conversely, if the primary goal is luring the animal to a specific site, where it is lured from might not matter. However, in some cases both source and destination do matter.

\subsection{Purposes for Baiting}

- Management baiting: Luring a wild animal to or from a specified site to achieve a management goal - e.g., capture or diversion away from a conflict zone.

- Harvest baiting: Luring a wild animal into a trap or within range of a weapon (e.g, bullet or arrow) so that it can be harvested.

- Research baiting: Luring a wild animal near observers or recording devices, or to habituate the animal to human presence, so it can be studied scientifically.

- Recreational baiting: Luring a wild animal to a site where it can be observed and perhaps photographed more readily or more enjoyably. This can foster habituation by the animal to humans.

\subsection{Diversionary Baiting}

Baiting wild animals to reduce likelihood of them conflicting with people. "Likelihood" encompasses probabilities of (a) occurrence, (b) frequency, and (c) intensity.

- Sympatric baiting: Providing the focal wildlife with non-conflict food (e.g., chow) at or near a conflict site within a conflict zone to reduce likelihood that the focal wildlife will forage on conflict foods near the conflict site (e.g., a neighborhood dumpster can inadvertently divert bears away from foraging at homes). Sympatric baiting need not change a focal animal's foraging locations; allopatric baiting attempts to do so.

- Allopatric baiting: Baiting at a non-conflict site to lure the focal wildlife away from a conflict zone. In the Tahoe Basin, placing bait sites $\sim 1 \mathrm{~km}$ from a conflict zone seemed optimum [6,9]; in Northeastern Minnesota, $0.4 \mathrm{~km}$ worked well [8] with black bears.

Baiting can have diverse effects. For example, baits that attract focal wildlife for harvest might simultaneously lure them away from conflict zones, and provide surviving animals with more nutrition. Harvest baiting near a popular hiking trail might lure the focal wildlife closer not only to the hunter, but also to the trail, thereby increasing likelihood that unsuspecting hikers will accidentally encounter the focal wildlife.

\subsection{Food Conditioning}

Classical definitions: Herrero $[1,2]$ defined food conditioning as wildlife learning to eat anthropogenic food, or as eating it repeatedly or habitually. The latter is sometimes mis-termed "food habituation." An alternate definition of food conditioning is "learning to associate anthropogenic food with people" [see 27] Those simplistic notions might suffice for some management purposes. But a 
more detailed understanding is advisable for research on its causes, consequences, and means of control.

\subsubsection{Respondant vs. instrumental conditioning}

The term "conditioning" originally referred to associative learning, of which the best known types are respondant and instrumental [26]. Respondant conditioning teaches animals cues that predict upcoming stimuli (e.g, teaching dogs to expect that food would be provided shortly after a bell sounded [see 27, 28]. Instrumental conditioning uses reward or punishment - i.e., feedback - to reinforce or extinguish selected behaviors [see 29]. In real world situations, both forms of conditioning often occur together.

- Respondant food conditioning: Learning to expect incursionary food $(I F)$ to be available near humans (or their odors), human use areas, or property (buildings, vehicles, or any other kind of artifact) [see 27, 28]. Humans or artifacts serve as predictive cues to where the conflict foods can be obtained. Learning to expect natural foods (e.g., berries or salmon) near humans is not considered food conditioning unless these foods have already been harvested by humans (e.g., whole salmon or salmon fillets in an angler's cooler or salmon offal discarded on the riverbank when the fish were filleted).

- Instrumental food conditioning: Learning that conflict foods are palatable or can be harvested profitably. [see 29]

\subsubsection{Proximal vs. distal food conditioning}

If bears seek anthropogenic food only in conflict zones, this is proximal food conditioning. If at locations remote from conflict zones, this is distal food conditioning.

\subsubsection{Situational food conditioning (FC)}

One or more of these seven categories could apply in a given case.

- Opportunistic FC: Eating $I F$ when it is found moreor-less by chance, and is consumed proportionately to its availability, relative to wild foods of comparable nutritional profitability.

- Transient FC: Seeking IF only briefly, e.g., while passing through a developed area while dispersing from the bear's natal range, or while migrating from one seasonal activity center to another.

- Compensatory FC: Seeking $I F$ mainly to the extent that preferred wild foods cannot be harvested profitably.

- Agonistically induced FC: Seeking IF mainly when prevented by enemies from obtaining sufficient wild foods.

- Preferential FC: Preferring $I F$ over wild food (this is a matter of degree). An animal is appropriately classified as preferentially food conditioned only if its consumption of $I F$ exceeds that food's availability relative to wild foods of comparable nutritional profitability within the animal's home range or territory.

- Location-specific FC: Seeking anthropogenic food only or mainly at a specific location.

- Person-specific FC: Seeking anthropogenic food only mainly from specific people.

\subsubsection{Direct vs. indirect human link}

Obtaining food from people directly (e.g., handouts) vs. indirectly (e.g., from a site where the food grew, was stored, or was discarded).

\section{Terminology Related to the Supply of a Specified Type of Food $\left(F_{i}\right)$}

\subsection{Presence}

Is $\mathrm{F}_{\mathrm{i}}$ present locally during that year or season?

\subsection{Abundance}

Gross amount of $F_{i}$ in a specified region (e.g., wildlife management unit, national park, or state).

\subsection{Accessibility}

The fraction of $F_{i}$ that the focal wildlife can access - a fraction that can be limited by physical barriers. For example, in some streams where salmon migrate toward spawning beds, they are accessible to bears mainly at sites where mobility of the salmon is constrained by shallow water, narrow channels, or swimming up a steep slope. So the fraction of a salmon school that is accessible to bears varies from one stream or section of stream to the next and according to fluctuations in water depth related to precipitation and melting of snow and ice.

\subsection{Availability}

Percent of the accessible $F_{i}$ not lost to (a) interspecific competition with vertebrates, invertebrates (e.g., insects), and fungi; (b) anti-predator precautions; (c) weather; or (d) human interference.

\subsection{Available Density}

Amount of $\mathrm{F}_{\mathrm{i}}$ available to bears per $100 \mathrm{~km}^{2}$.

\subsection{Profitability}

Nutrient-energy gain per unit effort or time. From an observer's perspective, profitability might be estimated from $F_{i}$ gain per unit effort or time. From an animal's perspective, this might be assessed by the amounts of effort and time required to achieve satiation; this is assumed to be a function of available density of $F_{i}$. Stringham [30] compared his rate 
of harvesting wild blue berries (Vaccinium alaskensis) with that of three orphaned wild black bear cubs that were habituated to him. As berry density per $\mathrm{m}^{2}$ declined over a period of weeks, harvest rates declined until both he and the cubs shifted the focus of their foraging from blueberries to other foods. Thereafter, blueberries were just a snack encountered opportunistically.

\subsection{Harvestability}

- Population Level: The fraction of the available $F_{i}$ that a focal population can profitably harvest despite constraints on its skill and its knowledge of when, where and how to harvest the food.

- Individual level: Fraction of the population-available $F_{i}$ that a focal individual can profitably harvest despite (a) intraspecific competition (e.g., via territoriality or dominance rank), as well as constraints on (b) its personal skill and its knowledge of when, where and how to harvest the food, and (c) its physical limitations (e.g., due to size, injury, etc.)

\subsection{Reliability}

Probability that $\mathrm{F}_{\mathrm{i}}$ will be available to the focal population or individual. From the animal's perspective, this is the strength of its anticipation that the food will be available, for instance in certain areas and times (e.g., ripe berries in alpine tundra or salmon in a particular stream).

\subsection{Attractiveness}

The power with which $\mathrm{F}_{\mathrm{i}}$ lures an animal to approach and sample it. This is assumed to be a function of the animal's anticipation that $F_{i}$ will be available, its appetite for $F_{i}$ perhaps based on having previously eaten $F_{i}$ and of pre-consumptive cues (e.g., olfactory, visual or auditory) as to the identify, profitability and palatability of $\mathrm{F}_{\mathrm{i}}$.

\subsection{Palatability}

The power with which $\mathrm{F}_{\mathrm{i}}$ motivates an animal to continue eating it once it has been sampled. Palatability is presumably correlated with the food's nutrient profitability relative to the animal's nutrient needs and to its hunger. Novelty can also be a factor.

\subsection{Appeal}

The appeal of $F_{i}$ is the resultant of its harvestability, reliability, attractiveness, and palatability

\subsection{Preference}

Which food is usually selected and eaten by an animal when it has a choice between two or more foods, assuming that all factors other than attractiveness and palatability, including microhabitat suitability, are equivalent among the foods.

\subsection{Microhabitat Characteristics}

This includes any other attractants associated with $\mathrm{F}_{\mathrm{i}}$, minus repulsion by any "repellants" associated with $F_{i}$ (appeal $=$ attractants - repellants).

\subsection{Microhabitat Suitability}

Suitable microhabitat tends to have sources of other foods, water, good escape cover, and perhaps shelter. It is also where the focal bear tends to feel safe, at least from wild enemies. By contrast, human settlements tend to be less suitable due in part to noxious odors, loud noises, belligerent dogs, and other repellants features. Suitability of settlements also includes the animal's risks of foraging there (e.g. of being shot or colliding with a motor vehicle).

\subsection{Selection}

The selections of when and where an animal forages and of what it consumes are assumed to be functions of the food's harvestability and appeal, the animal's preferences, and suitability of its microhabitat.

\section{REFERENCES}

[1] S. Herrero. Bear Attacks: Their Causes And Avoidance. Lyons Press, Piscataway, New Jersey, USA. 1985.

[2] S. Herrero, S. Fleck. Injury to people inflicted by black, grizzly or polar bears: Recent trends and new insights. Ursus 8:25-32. 1990.

[3] S. Herrero, A. Higgins. Human injures inflicted by bears in British Columbia 1960-1997. Ursus 11:209-218. 1999.

[4] S. Herrero, A. Higgins 2003. Human injuries inflicted by bears in Alberta 1960-1998. Ursus 14:44-54. 2003.

[5] S. Herrero, A. Higgins, J.E. Cardoza, L.I. Hajduk, T.S. Smith. Fatal attacks by American black bear on people 1900-2009. J. Wildlife Management 75(3):596-603. 2011.

[6] S. F. Stringham, A. Bryant. Distance-dependent effectiveness of diversionary bear bait sites. Human-Wildlife Interactions 9: 229-235. 2015.

(http://berrymaninstitute.org/htm/human-wildlife-interactions /fall-2015)

[7] A. Bryant. Unpublished data.

[8] L. L. Rogers. Does diversionary baiting create nuisance bears and jeopardize public safety? Human-Wildlife Interactions 5:287-295. 2011.

[9] S. F. Stringham, A. Bryant. Distance-dependent effectiveness of diversionary bear bait sites: Commentary. Human-Wildlife Interactions 10: 128-131. 2016. 
(http://berrymaninstitute.org/htm/human-wildlife-interactions /spring-2016)

[10] J. R. Krebs, N. B. Davies. An Introduction to Behavioral Ecology. 4th ed. Oxford: Blackwell Scientific Publications. 1989.

[11] R. H. Flowers. Supplemental baiting of black bears in tree-damaged areas of western Washington. Pages 147-148 in Proceedings of animal damage management in Pacific Northwest forest symposium. Washington State University, Pullman, Washington, USA. 1986.

[12] R. H. Flowers. Annual report: animal damage control service. Washington Forest Protection Association. Olympia, Washington, USA. 1988.

[13] G. Ziegltrum. Efficacy of black bear supplemental baiting to reduce conifer damage in western Washington. J. Wildlife Management 68:470-474. 2004.

[14] G. Ziegltrum. Impacts of the black bear supplemental baiting program on ecology in western Washington. Human-Wildlife Conflicts 2:153-159. 2008.

[15] K. Dutton, S. Miller, T. DeBruyn. Polar bear diversionary feeding workshop report. USFWS report. 38 pp. + Append. 2012.

[16] A. Derocher, J. Aars, S. C. Amstrup, A. Cutting, N. J. Lunn, P. K. Molnár, M. E. Obbard, I. Stirling, G. W. Thiemann, D. Vongraven, Ø. Wiig, G. York. Rapid ecosystem change and polar bear conservation. Conservation Letters. 2013. DOI: $10.1111 /$ conl.12009.

[17] I. Kavčič, M. Adamič, P. Kaczensky, M. Krofel, K. Jerina. Supplemental feeding with carrion is not reducing brown bear depredations on sheep in Slovenia. Ursus 24(2):111-119. 2013.

[18] K. A. Gunther, M.A. Haroldson, K.F. Steven, L. Cain, J. Copeland, C.C. Schwartz. Grizzly bear-human conflicts in the Greater Yellowstone ecosystem, 1992-2000. Ursus 15:10-22. 2004.
[19] L. L. Rogers, S. A. Mansfield. 2011. Can food lead black bears out of trouble? [invited talk]. 20th International Conference on Bear Research \& Management, Ottawa, Ontario. July 17-23, 2011. (Abstract)

[20] J. Sterba. Nature wars. Crown Pub., New York, NY. 2012.

[21] V. Geist. Response to Rogers and Mansfield (2011) and Stringham (2011). Human-Wildlife Interactions 5: 192-196. 2011.

[22] R. E. Hoare. Determinants of human-elephant conflict in a land-use mosaic. Journal Applied Ecology 36: 689-700. 1999.

[23] L. E. King, I. Douglas-Hamilton, F. Vollrath. Bee hives as effective deterrents for crop raiding elephants: field trials in northern Kenya. African Journal Ecology. 49: 431-439. 2011.

[24] M. Pai, S. Aliwo. A Survey of attitudes towards humanbaboon conflicts in a university campus in Ethiopia. J. Biodivers. Manage Forestry 3: 1-2. 2014.

[25] State of Oregon v. Karen Jean Noyes, case 083494/08-2001

[26] M. R. Denny, S. C. Ratner. Comparative Psychology: Research In Animal Behavior. Dorsey Press. Homewood, IL. 1970 .

[27] S. Herrero, T. Smith, T.D. Debruyn, K. Gunther, and C.A. Matt. From the Field: brown bear habituation to people safety, risks, and benefits. Wildlife Society Bulletin 33:362373. 2005

[28] J. B. Hopkins III, S. Herrero, R. Shideler, K. A. Gunther, C. C. Schwartz, and S. T. Kalinowski. A proposed lexicon of terms and concepts for human-bear management in North America. Ursus 21: 154-168. 2010.

[29] D. R. McCullough. Behavior, bears, and humans. Wildlife Society Bulletin 10:27-33. 1982.

[30] S. F. Stringham. Beauty Within The Beast: Kinship With Bears In The Alaska Wilderness (2nd edition). WildWatch, Soldotna, AK. 2013. 